\title{
Percepção de trabalhadores rurais quanto aos efeitos toxicológicos do uso e exposição a agrotóxicos
}

Os trabalhadores rurais têm utilizado cada vez mais agrotóxicos em suas plantações. O uso intenso e a falta de informações sobre os reais fatores de risco desenvolvidos por esses produtos podem causar inúmeros prejuízos à saúde. O objetivo deste estudo foi avaliar a percepção dos trabalhadores rurais frente aos sintomas causados à saúde pelos agrotóxicos. Para isso, foram investigadas as principais queixas dos trabalhadores em relação à saúde, tempo de atividade rural, uso de agrotóxicos e o conhecimento das toxidades destes produtos. Para isso, foi utilizado um questionário, uma entrevista e uma tabela contendo efeitos sintomatológicos desenvolvidos pelo uso e/ou exposição de agrotóxicos à saúde. Participaram da pesquisa 40 trabalhadores rurais que atuavam na agricultura familiar ou agroecológica dos municípios que compõem a Zona da Mata de Rondônia. Os resultados mostram que $72,5 \%$ dos entrevistados apresentaram sintomas crônicos relacionados à saúde física e psicológica. A percepção dos riscos e prejuízos causados à saúde humana pelos agrotóxicos são desconhecidos pelos entrevistados, embora, $60 \%$ estão na área rural e utilizam agrotóxicos a mais de 30 anos. 0 uso descontrolado e intenso de vários tipos de agrotóxicos e a falta de conhecimento sobre os reais danos causados à saúde está contribuindo para o adoecimento dos trabalhadores rurais, agravando ainda mais a situação de vulnerabilidade a que eles se encontram. Isso mostra que existe a necessidade de ações e/ou iniciativas de vigilância em saúde do trabalhador para trazer orientações e assistência técnica adequada quanto ao uso seguro e os reais danos causados à saúde pelos agrotóxicos.

Palavras-chave: Saúde do trabalhador; Sofrimento Psíquico; Amazônia.

\section{Rural workers' perception of the toxicological effects of pesticide use and exposure}

Rural workers are increasingly using pesticides in their plantations. Heavy use and lack of information about the actual risk factors developed by these products can cause numerous health hazards. The objective of this study was to evaluate the perception of rural workers regarding the symptoms caused to health by pesticides. For this, the main complaints of workers regarding health, time of rural activity, use of pesticides and knowledge of the toxicity of these products were investigated. For this, we used a questionnaire, an interview and a table containing symptomatological effects developed by the use and / or exposure of pesticides to health. Forty rural workers who worked in family or agroecological agriculture of the municipalities that make up the Zona da Mata de Rondônia participated in the research. Results show that $72.5 \%$ of respondents had chronic symptoms related to physical and psychological health. The perception of the risks and harms caused to human health by pesticides is unknown to respondents, although $60 \%$ are in rural areas and use pesticides for over 30 years. The uncontrolled and intense use of various types of pesticides and the lack of knowledge about the real damage caused to health is contributing to the illness of rural workers, further aggravating their vulnerability situation. This shows that there is a need for actions and / or initiatives for occupational health surveillance to bring guidance and adequate technical assistance regarding the safe use and the actual damage caused to health by pesticides.

Keywords: Worker's health; Psychic suffering; Amazon.

Topic: Desenvolvimento, Sustentabilidade e Meio Ambiente

Reviewed anonymously in the process of blind peer.
Received: 02/06/2019

Approved: 05/08/2019
Rosani Teresinha da Silva Stachiw

Universidade Federal de Rondônia, Brasil

http://lattes.cnpq.br/6361629035673913

http://orcid.org/0000-0002-5162-7810

rosani.stachiw@gmail.com
Referencing this:

STACHIW, R. T. S.. Percepção de trabalhadores rurais quanto aos efeitos toxicológicos do uso e exposição a agrotóxicos. Nature and Conservation, v.12, n.2, p.11-18, 2019. DOI: http://doi.org/10.6008/CBPC2318-2881.2019.002.0002 


\section{INTRODUÇÃO}

O uso indiscriminado de agrotóxicos no Brasil vem crescendo ao longo do tempo, causando consequências graves, como a contaminação de alimentos, do meio ambiente (SILVA et al., 2014), intoxicações e morte a partir do trabalho no campo (ABRASCO, 2015). Estima-se que, entre trabalhadores de países em desenvolvimento, os agrotóxicos causam anualmente 70 mil intoxicações agudas e crônicas que evoluem para óbito de acordo com a Organização Internacional do Trabalho (OIT) e, pelo menos, 7 milhões de doenças agudas e crônicas não-fatais (FARIA et al., 2007). Isso reflete diretamente nos gastos públicos com tratamentos de intoxicações, afastamento e aposentadoria por invalidez e perdas econômicas na agricultura (LIMA, 2008).

A incidência de intoxicações por agrotóxicos no Brasil foi de 6,23 casos por 100 mil habitantes em 2013 (BRASIL, 2016). No período de 2007 a 2014 houve um aumento de 87\% dos casos notificados, sendo que o total acumulado no período alcançou 68.873 casos (ABRASCO, 2015). Os agrotóxicos com o princípio ativo glifosato são os mais utilizados no Brasil desde 2008 (BRASIL, 2016). O glifosato é apontado como causador de doenças neurodegenerativas, como Parkinson e doença de Alzheimer (ALMEIDA et al., 2016), distúrbios reprodutivos, infertilidade (ALMEIDA et al., 2016) e cancerígeno (PIGNATI et al., 2017).

Vários problemas à saúde são associados ao uso e exposição aos agrotóxicos com efeitos de intoxicações agudas, subagudas e crônicas (ARAÚJO et al., 2013). A intoxicação crônica é a mais difícil de ser associado ao uso dos agrotóxicos devido ao tempo elevado para apresentação dos sintomas, ocultando os sintomas de adoecimento físico e psicológico (NEVES et al., 2013).

Os problemas causados pelos efeitos nocivos dos agrotóxicos à saúde permeiam por todo núcleo familiar, por meio da contaminação intradomiciliar (SENA, 2018). Dentre todos os grupos, os mais vulneráveis às intoxicações por agrotóxicos são os trabalhadores rurais, seguidos de crianças, gestantes, lactentes, idosos e pessoas com problemas de saúde de modo geral (CASSAL et al., 2014). A intoxicação ocorre devido à falta de orientação e assistência técnica adequada oferecida a estes indivíduos, tanto em sua regularidade quanto em qualidade (ambiental e humana), a ausência de cuidados em seu manuseio, a falta do uso do Equipamento de Proteção Individual (EPI) (LONDRES, 2011), a facilidade de acesso e o incentivo ao uso desses produtos (SANTANA et al., 2016).

Dada a complexidade da temática, sobretudo por esta pesquisa se desenvolver na Região Amazônica, ainda muito ausente de estudos nesta área, é fundamental compreender a percepção e o conhecimento que os trabalhadores rurais têm em relação aos efeitos toxicológicos do uso e exposição aos agrotóxicos. Neste trabalho a hipótese é de que os trabalhadores rurais investigados não identificam a relação direta do uso e da exposição aos agrotóxicos aos problemas de saúde sofridos. Neste estudo optou-se em utilizar a metodologia de análise de percepção de acordo com Faria et al. (2007), com base nas crenças, conhecimentos adquiridos e experiência do indivíduo em relação a vários aspectos do uso de agrotóxicos.

Ficou evidenciado que os trabalhadores expostos aos agrotóxicos apresentaram sintomatologia física e psicológica, porém, não percebem ou negam que os efeitos toxicológicos sentido por eles, principalmente, 
os de efeitos crônicos, que são ocasionados pelo tempo de exposição submetido a essa atividade e aos agrotóxicos. A partir dos resultados da pesquisa, espera-se contribuir com o desenvolvimento da ciência e de ações e/ou iniciativas de vigilância em saúde do trabalhador para trazer orientações e assistência técnica adequada quanto ao uso seguro e os reais danos causados à saúde pelos agrotóxicos.

\section{METODOLOGIA}

A área da pesquisa foi o Território Rural da Zona da Mata de Rondônia, Região Norte do Brasil, composto por sete municípios: Alta Floresta D'Oeste, Alto Alegre dos Parecis, Castanheiras, Nova Brasilândia D'Oeste, Novo Horizonte do Oeste, Rolim de Moura e Santa Luzia D'Oeste. A população urbana da área de estudo é de 74.530 hab. e rural de 55.901 hab., onde se predomina o trabalho rural do tipo familiar, criação animal (suíno, bovinos, galináceos) e o cultivo de cítricos, hortaliças, café, feijão, cacau, pimenta do reino, tomate, banana, entre outras culturas.

O estudo de campo aconteceu entre janeiro e março de 2018. Para o levantamento dos dados foi utilizado um questionário semiestruturado adaptado de Luz et al. (2015), contendo perguntas a respeito das variáveis demográficas (sexo, idade, cor/etnia, estado civil, escolaridade), socioeconômicas (função de trabalho, carga horária de trabalho, utilização de agrotóxicos, tempo de trabalho rural, renda familiar), além de uma entrevista.

A entrevista buscou caracterizar o processo de trabalho, com questões sobre a percepção de riscos à saúde em decorrência do contato direto com os agrotóxicos, intoxicação sofrida durante ou após a aplicação de agrotóxicos, queixas relacionadas à saúde, acompanhamento médico e uso de medicamento. Após a entrevista, foi apresentada uma tabela contendo 22 sintomas que são desenvolvidos por intoxicações a agrotóxicos (ANVISA, 2011; BRASIL, 2017).

A amostra foi composta por quarenta $(\mathrm{N}=40)$ trabalhadores rurais, sendo 33 praticantes da agricultura convencional e 7 em transição agroecológica. As propriedades foram escolhidas aleatoriamente, sendo, no mínimo, cinco propriedades em cada município da região com participação voluntária dos trabalhadores rurais de ambos os sexos. Os critérios de inclusão foram os trabalhadores com idades entre 25 e 65 anos e que tivesse trabalhando ativamente na área rural. Utilizou-se como critério de exclusão, ser membro da mesma família, considerando o primeiro grau de parentesco, tendo em vista que o objeto do estudo não foi a família.

Este estudo foi aprovado pelo comitê de ética em pesquisa da Universidade Federal de Rondônia (UNIR), CAAE: 80685017. O consentimento livre e esclarecido foi lido e assinado pelos participantes antes do estudo. Após a tabulação dos resultados, os dados foram submetidos à análise estatística descritiva para a identificação dos percentuais das respostas recorrentes.

\section{RESULTADOS E DISCUSSÃO}

\section{Caracterização sociodemográfico e condições gerais de vida e saúde}


A maioria dos trabalhadores é do sexo masculino $(72,5 \%)$, de cor parda $(65 \%)$, casados $(77,5 \%)$, com idades entre 36 e 50 anos (45\%) e com baixo nível de escolaridade (67,5\%). Destes, $60 \%$ estão na área rural a mais de 30 anos. $O$ trabalho rural começa para muitos ainda na infância, principalmente na agricultura de subsistência, como é o caso da agricultura familiar. Rondônia foi palco de uma intensa migração nas décadas de 70 e 80 (GOMES, 2012), período de chegada dos entrevistados e seus familiares na região.

O uso de agrotóxicos pelos produtores rurais é intenso e diversificado, sendo aplicado 'sempre que precisa', não respeitando o intervalo de aplicação e o período de carência. Dos entrevistados, $75 \%$ utilizam mais de um tipo de agrotóxico, $15 \%$ não souberam informar os nomes dos agrotóxicos utilizados e os demais (10\%) estão em transição agroecológica, apesar de próximos às suas propriedades ser comum a presença de cafezais ou outras culturas que demandam o uso de agrotóxicos. Estes produtos são carregados pela ação do vento e acabam por afetar a produção e os próprios trabalhadores (LONDRES, 2011). Além disso, alguns 'agroecológicos' (5\%) também declaram usar o herbicida mata-mato (glifosato) para diminuir a vegetação que cresce ao lado das plantações ou das pastagens.

O herbicida com o princípio ativo glifosato é o mais utilizado pelos entrevistados (80\%). Além desse, outros agrotóxicos com o princípio ativo paraquat, e outros da categoria dos Piretroides e Carbamatos também foram listados. Os inseticidas da classe dos organofosforados atuam no organismo humano inibindo um grupo de enzimas denominadas colinesterases (CAVALCANTE et al., 2016). Essas enzimas agem na degradação da acetilcolina, um neurotransmissor responsável pela transmissão dos impulsos no sistema nervoso (central e periférico), causando diversos distúrbios chamados de crise colinérgica (PERES et al., 2003) que vão desde dores de cabeças a tremores, incluindo tonturas à perda de consciência e desmaios.

A maior parte destes agrotóxicos utilizados pelos trabalhadores pertence à classe toxicológica I e II (extremamente tóxico e altamente tóxico, respectivamente). Considerando esta classificação, pode-se afirmar que esses trabalhadores, principalmente os manipuladores e pulverizadores estão expostos às substâncias que podem trazer sérios prejuízos à saúde e ao meio ambiente (SENA, 2018). A classificação toxicológica dos agrotóxicos é ilusória, pois, não existe uso seguro dessas substâncias, todos os agrotóxicos são tóxicos ao ser humano e ao meio ambiente, independente do grau (ANVISA, 2011).

A baixa escolaridade dos agricultores é apontada como um problema de intoxicações por agrotóxicos, na medida em que isto dificulta a leitura de recomendações de segurança contida no rótulo (FARIA et al., 2007). O rótulo pode auxiliar nessa função, indicando o uso adequado e instruindo como diminuir os impactos adversos ao meio ambiente e à saúde humana (SANTANA et al., 2016). Apesar de 80\% dos trabalhadores declararem possuir o hábito de ler as informações contidas nos rótulos/bulas das embalagens de agrotóxicos, $65 \%$ destes trabalhadores desconhecem as classes dos produtos e o real perigo a que estão expostos. Prova disso, é que 35\% dos entrevistados relatam consumir bebidas (café, água, leite) durante os intervalos das aplicações dos agrotóxicos, favorecendo outra via de contaminação (boca), quando se manuseiam alimentos e bebida com as mãos contaminadas (ANVISA, 2011).

O alto consumo de agrotóxicos está relacionado com a falta de conhecimento, acompanhamento profissional inadequado e a facilidade de aquisição dos mesmos (SANTANA et al., 2016; SENA, 2018). É de 
praxe a venda de agrotóxicos aos entrevistados por meio de um cadastro simples em lojas do ramo, estando em desacordo com a Lei Federal 7.802/89, que exige acompanhamento profissional in loco antes da venda dos produtos. Nestes estabelecimentos, a indicação do cálculo da dosagem é feita de acordo com o rótulo do produto, indicado pelo vendedor ou o próprio agricultor faz a dosagem por meio aleatório.

$\mathrm{Na}$ agricultura de subsistência, todos os membros da família participam do trabalho na lavoura. Poupadas da exposição nas pulverizações, as mulheres ajudam no processo da colheita e são responsáveis pela lavagem das roupas sujas de agrotóxicos (SENA, 2018). Isso foi verificado durante o presente estudo, onde $67,5 \%$ dos entrevistados declararam que as roupas utilizadas para aplicação dos agrotóxicos eram lavadas juntamente com as demais roupas da família. O trânsito dos familiares, inclusive crianças, pelas lavouras e pastos usando bermuda e chinelos também é comum nas áreas investigadas. $O$ conjunto dessas ações potencializa a contaminação dos trabalhadores e seus familiares (LONDRES, 2011).

Apesar de $87,5 \%$ dos entrevistados relatarem receber algum tipo de orientação quanto a proteção dos agrotóxicos, o EPI é usado apenas por $32,5 \%$ dos trabalhadores. As razões pelo não uso do EPI é devido ao desconhecimento sobre os riscos a que se expõe e ao desconforto do equipamento de proteção, o clima da região e a redução de mobilidade que dificultam e atrasam a conclusão do trabalho.

Entre os que dizem 'usar sempre' e 'às vezes' (37,5\%), observou-se (in loco) que as roupas para a proteção durante a preparação da cauda e/ou a pulverização dos agrotóxicos eram roupas comuns do dia a dia (camisa, calça, boné, tênis ou chinelo), estando em desacordo com os manuais de segurança (ANVISA, 2011). Os entrevistados não consideram como variáveis importantes para a sua proteção o tipo de equipamento utilizado na operação e os níveis reais de exposição e, até mesmo, as características ambientais (horário de aplicação). Devido a isso, $72,5 \%$ sofreram algum tipo de intoxicação, e como consequência, 62,5\% apresentam sintomatologia física e 10\% sintomatologia de ordem psicológica.

As principais queixas para $72,5 \%$ dos trabalhadores foram: diabetes $(7,5 \%)$, dores de cabeça crônica (15\%), dores na coluna $(17,5 \%)$, hipertensão arterial (5\%), problemas renais $(10 \%)$, desânimo e ansiedade (5\%), depressão (5\%), insônia e irritação (5\%) e câncer (2,5\%). A maioria destes (45\%) fazem uso de algum tipo de medicamento e $10 \%$ fazem acompanhamento psiquiátrico. Entretanto, por mais grave que posa parecer estes números, a realidade é que eles estão muito além de representar o número real das intoxicações por agrotóxico na área rural (FARIA et al., 2007).

\section{Percepção dos sintomas relacionados aos agrotóxicos}

Os sintomas das intoxicações agudas (dor de cabeça, tontura, ânsia de vômito, irritação na pele e nos olhos) causados pelos agrotóxicos são mais bem percebidos pelos agricultores investigados (tabela 1). Nestes tipos de intoxicações, os sintomas aparecem em poucas horas, facilitando a percepção, o diagnóstico e o tratamento do trabalhador (VIERO et al., 2016). Entretanto, estes sintomas são frequentemente negligenciados, ficando seu tratamento condicionado a chás caseiros que 'desintoxicam o organismo' e os sintomas desaparecem em 'poucas horas'. Este fato reforça a baixa procura por atendimento hospitalar conforme os dados da pesquisa. 
Tabela 1: Percepção quanto aos sintomas de intoxicações, causadas pelo uso e/ou exposição a agrotóxicos.

\begin{tabular}{|r|c|r|c|}
\hline \multicolumn{2}{|c|}{ Porcentagem de entrevistados $(\boldsymbol{N}=\mathbf{4 0})$} & Sintomas & Não percebem \% \\
\hline Sintomas & Não percebem \% & Diarreia & 62 \\
\hline Dor de cabeça & 30 & Tosse & 75 \\
\hline Irritabilidade & 77,5 & Hepressão & 100 \\
\hline Tontura & 37,5 & Nervosismo & 100 \\
\hline Dores abdominais & 72,5 & Dificuldade para respirar & 100 \\
\hline Desânimo & 100 & Esquecimentos & 100 \\
\hline Insônia & 100 & Irritação na pele & 32,5 \\
\hline Tensão muscular & 80 & Irritação nos olhos & 32,5 \\
\hline Imunidade baixa & 70 & Problemas renais & 100 \\
\hline Tristeza & 100 & Problemas hormonais & 100 \\
\hline Ansia de vomito & 32,5 & & \\
\hline
\end{tabular}

A irritabilidade, dores abdominais, tensão muscular, imunidade baixa, nervosismo, diarreia e tosse não foram percebidos pela maioria dos trabalhadores como sintomas causados pelos agrotóxicos. Isso se deve à sintomatologia ser mais difusa, podendo ser confundida com outras patologias comuns em áreas rurais, como parasitoses do sistema digestivo, disenteria e viroses (OLIVEIRA-SILVA et al., 2003), ou ainda, o uso simultâneo da mistura de produtos com características químicas e toxicológicas diferentes, ainda pouco conhecidos pela ciência.

Existe também a resistência do trabalhador em reconhecer em si sintomas de intoxicação ou admitir que seja devido ao uso dos agrotóxicos, pois sempre há relatos de que parentes, vizinhos ou amigos se intoxicaram devido ao uso ou exposição aos agrotóxicos. A falta de informações associada à negação inconsciente faz com que os trabalhadores passem a não acreditar na existência de riscos diretos a saúde, por mais evidentes que possa parecer (GREGOLIS et al., 2012).

Com o passar do tempo, os problemas de saúde vindo dos agrotóxicos podem piorar e provocar danos maiores, pois alguns produtos são bioacumuladores e causam doenças tardias (difícil de ser identificada) e até mais graves (OLIVEIRA-SILVA et al., 2003; ANVISA, 2011). Devido a isso, provavelmente, os trabalhadores não perceberam a relação entre os agrotóxicos e a sintomatologia crônica (desânimo, insônia, tristeza, esquecimento, problemas renais e hormonais, dificuldades para respirar, depressão e hipertensão) (tabela 1).

A ansiedade não foi percebida por $90 \%$ dos entrevistados como sendo desenvolvida pelos agrotóxicos, embora ela tenha sido a maior queixa dos entrevistados (60\%), sendo $5 \%$ já diagnosticados com depressão e $5 \%$ com ansiedade. Dos que apresentaram estes sintomas, somente $(7,5 \%)$ fazem uso de ansiolíticos e antidepressivos. Este cenário oferece uma situação de risco ainda maior, pois há um alto índice de suicídio na área rural, inclusive por jovens que utilizam o próprio veneno para cometer tal ato (ABRASCO, 2015). Estima-se que, anualmente, mais de 800 mil pessoas morrem por suicídio e, a cada adulto que se suicida, pelo menos outros 20 atentam contra a própria vida. Entre os fatores de risco para o suicídio estão os transtornos mentais, como depressão, o isolamento social e psicológicos (BRASIL, 2017)

\section{CONCLUSÕES}

Os trabalhadores entrevistados presente na região amazônica demonstraram um nível de conhecimento insatisfatório com relação aos riscos toxicológicos causados pelos agrotóxicos e não percebem 
a relação direta entre o uso de agrotóxicos e os problemas de saúde sofridos, principalmente os crônicos (problemas hormonais, problemas renais, hipertensão, ansiedade, depressão) devido ao tempo elevado para apresentação dos sintomas.

O estudo se mostrou relevante pela identificação de que muitos trabalhadores rurais estão expostos e sem informações concretas dos reais danos causados pelas intoxicações por agrotóxicos, adicionalmente, com a falta de proteção pessoal durante o manuseio e a pulverização dos produtos, a situação de vulnerabilidade a que se encontram se agrava ainda mais.

Por fim, na tentativa de amenizar o cenário preocupante identificado neste estudo, indica-se a adoção de estratégias e ações simultâneas de diferentes competências e saberes como o efetivo funcionamento do Programa Nacional de Redução de Agrotóxicos - PRONARA, juntamente com a sociedade civil organizada.

É igualmente necessário estabelecer e cobrar compromissos de qualificação e treinamento, construindo estratégias de gerenciamento de riscos associados a ações que possam capacitar não só os trabalhadores rurais, mas, também seus familiares, para um maior esclarecimento sobre os reais riscos advindos desta exposição e assim contribuir para a melhor compreensão do nexo causal em saúde/adoecimento em prol da saúde de populações expostas. Outra medida seria ampliar o financiamento para a agroecologia e a produção de alimentos orgânicos, investir em pesquisas voltadas para o controle de pragas e as práticas sustentáveis de agropecuária.

\section{REFERÊNCIAS}

ABRASCO. Associação Brasileira de Saúde Coletiva. Um alerta sobre os impactos dos agrotóxicos na saúde. Rio de Janeiro: ABRASCO, 2015.

ALMEIDA, L.; ÁlVARO, A. C.; TEIXEIRA, A. A. C.; BEZERRA, N. S.; TEIXEIRA, V. W.. Efeito protetor da melatonina sobre intoxicações por herbicidas. Pesquisa Veterinária Brasileira, v.36, n.3, p.174-180, 2016. DOI:

http://doi.org/10.1590/S0100-736X2016000300005

ANVISA. Agência Nacional de Vigilância Sanitária. Cartilha sobre Agrotóxicos: Série Trilhas do Campo. Brasília: ANVISA, 2011.

ARAÚJO, J. N. G.; GREGGIO, M. R.; PINHEIRO, T. M. M.. Agrotóxicos: a semente plantada no corpo e na mente dos trabalhadores rurais. Psicologia em Revista, Belo Horizonte, v.19, n.3, p.389-406, 2013. DOI:

http://doi.org/10.5752/P.1678-9563.2013v19n3p389

BRASIL. Decreto n.4074 de 04 de janeiro de 2002.

Regulamenta a Lei n.7802 de 11 de julho de 1989. Lei dos agrotóxicos. Brasília: DOU, 2002.

BRASIL. Ministério da Saúde. Boletim Epidemiológico, Brasília: MS, 2017.

BRASIL. Ministério da Saúde. Relatório Nacional de Vigilância em Saúde de Populações Expostas a Agrotóxicos. Brasília: MS, 2016.
CASSAL, V. B.; AZEVEDO, L. F. A.; FERREIRA, R. P.; SILVA, D. G.; SIMÃO, R. S.. Agrotóxicos: uma revisão de suas consequências para a saúde pública. Revista Eletrônica em Gestão, Educação e Tecnologia Ambiental, v.18, n.1, p.437445, 2014. DOI: http://doi.org/10.5902/2236117012498

CAVALCANTI, L. P. A. N.; AGUIAR, A. P.; LIMA, J. A.; LIMA, A. L. S. Intoxicação por Organofosforados: Tratamento e Metodologias Analíticas Empregadas na Avaliação da Reativação e Inibição da Acetilcolinesterase. Revista Virtual de Química, v.8, n.3, p.739-766, 2016. DOI:

http://doi.org/10.5935/1984-6835.20160056

FARIA, N. M. X.; FASSA, A. C. G.; FACCHINI, L. A.. Intoxicação por agrotóxicos no Brasil: os sistemas oficiais de informação e desafios para realização de estudos epidemiológicos.

Ciência \& Saúde Coletiva, Rio de Janeiro, v.12, n.1, p.25-38, 2007. DOI: http://doi.org/10.1590/S141381232007000100008

GOMES, E.. História e geografia de Rondônia. Vilhena: Express, 2012.

GREGOLIS, T. B. L.; PINTO, W. J.; PERES, F.. Percepção de riscos do uso de agrotóxicos por trabalhadores da agricultura familiar do município de Rio Branco, AC. Revista Brasileira de Saúde Ocupacional, v.37, n.125, p.99-113, 2012. DOI: http://doi.org/10.1590/S0303$\underline{76572012000100013}$ 
LIMA, P. J. P.. Possíveis doenças físicas e mentais relacionadas ao manuseio de agrotóxicos em atividades rurais, na região de Atibaia, SP-Brasil. Cadernos Brasileiros de Saúde Mental, Florianópolis, v.7, n.15, p.81-121, 2015.

LONDRES, F.. Agrotóxicos no Brasil: um guia para ação em defesa da vida. Rio de Janeiro: 2011.

LUZ, V. G.; SIQUEIRA, C. E. G.; LA-ROTTA, E. I. G.; MIQUILIN, I. O. C.; CORREIA FILHO, H. R. Segurança alimentar e nutricional, autopercepção da saúde e uso de Agrotóxicos: o caso dos agricultores familiares de Ibiúna, São Paulo.

Segurança Alimentar e Nutricional, Campinas, v.22, n.2, p.729-741, 2015.

MAGALHÃES, M. A. S.. Exposição a agrotóxicos na atividade agrícola: um estudo de percepção de riscos à saúde dos trabalhadores rurais no distrito de Pau Ferro: Salgueiro-PE. Recife: FIOCRUZ, 2010.

NEVES, P. D. M.; BELLINI, M. Intoxicações por agrotóxicos na mesorregião norte central paranaense, Brasil: 2002 a 2011. Ciência \& Saúde Coletiva, v.18, n.11, p.3147-3156, 2013. DOI: http://doi.org/10.1590/S1413-81232013001100005

OLIVEIRA-SILVA, J. J.; MEYER, A.. Sistema de notificação de intoxicações: o fluxograma da joeira. In: PERES, F.; MOREIRA, J. C.. É veneno ou é remédio?. Agrotóxicos, Saúde e Ambiente, Rio de Janeiro, p.317-326, 2003.

PAGANELLI, A.; GNAZZO, V.; ACOSTA, H.; LÓPEZ, S. L.; CARRASCO, A. E. Glyphosate-based herbicides produce teratogenic effects on vertebrates by impairing retinoic acid signaling. Chemical Research in Toxicology, v.23, p.15861595, 2010. DOI: http://doi.org/10.1021/tx1001749

PERES, F.; MOREIRA, J. C.; DUBOIS, G. S.. Agrotóxicos, saúde e ambiente: uma introdução ao tema. In: PERES, F.; MOREIRA, J. C.. É veneno ou é remédio?. Agrotóxicos, saúde e ambiente, Rio de Janeiro, p.21-41, 2003.

PIGNATI, W. A.; LIMA, F. A. N. S.; LARA, S. S.; CORREA, M. L. M.; BARBOSA, J. R.; LEÃO, L. H. C.; PIGNATTI, M. G.

Distribuição espacial do uso de agrotóxicos no Brasil: uma ferramenta para a Vigilância em Saúde. Ciência \& Saúde

Coletiva, v.22, n.10, p.3281-3293, 2017. Dol:

http://doi.org/10.1590/1413-812320172210.17742017

SAMSEL, A.; SENEFF, S.. Glyphosate, pathways to modern diseases III: Manganese, neurological diseases, and associated pathologies. Surgical Neurology International, p.45, 2015. Dol: http://doi.org/10.4103/2152-7806.153876

SAMSEL, A.; SENEFF, S.. Glyphosate's Suppression of Cytochrome P450 Enzymes and Amino Acid Biosynthesis by the Gut Microbiome: Pathways to Modern Diseases. Entropy, v.15, n.4, p.1416-1463, 2013. DOI: http://doi.org/10.3390/e15041416

SANTANA, C. M.; COSTA, A. R.; NUNES, R. M. P.; PERON, A. P.; MELO-CAVALCANTE, A. A. C.; FERREIRA, P. M. P.. Exposição ocupacional de trabalhadores rurais a agrotóxicos. Cadernos de Saúde Coletiva, Rio de Janeiro, v.24, n.3, p.301307, 2016. DOI: http://doi.org/10.1590/1414462×201600030199

SENA, T. R. R.; DOURADO, S. S. F.; ANTONIOLLI, A. R.. Audição em altas frequências em trabalhadores rurais expostos a agrotóxicos. Ciência \& Saúde Coletiva, n.212 2018.

SILVA, F. M.; ANDRADE SOBRINHO, L. G.; COELHO, D. C.; FERREIRA, P. M. L.; AZEVEDO, P. B.. Percepção de risco no uso de agrotóxicos em cinco comunidades rurais no município de Pombal-PB. Revista Verde de Agroecologia e Desenvolvimento Sustentável, Pombal, v.9, n.5, p.1-9, 2014.

SIQUEIRA, D. F.; MOURA, D.; ROMERO, C. L.; ARAÚJO, G. E.; CRUZ, A. J. L.. Análise da exposição de trabalhadores rurais a agrotóxicos. Revista Brasileira em Promoção da Saúde, v.26, 2013.

VIERO, C. M.; CAMPONOGARA, S.; CEZAR-VAZ, M. R.; COSTA, V. Z.; BECK, C. L. C.. Sociedade de risco: o uso dos agrotóxicos e implicações na saúde do trabalhador rural. Escola Anna Nery, v.20, n.1, p.99-105, 2016. DOI: http://doi.org/10.5935/1414-8145.20160014

A CBPC - Companhia Brasileira de Produção Científica (CNPJ: 11.221.422/0001-03) detém os direitos materiais desta publicação. Os direitos referem-se à publicação do trabalho em qualquer parte do mundo, incluindo os direitos às renovações, expansões e disseminações da contribuição, bem como outros direitos subsidiários. Todos os trabalhos publicados eletronicamente poderão posteriormente ser publicados em coletâneas impressas sob coordenação da Sustenere Publishing, da Companhia Brasileira de Produção Científica e seus parceiros autorizados. Os (as) autores (as) preservam os direitos autorais, mas não têm permissão para a publicação da contribuição em outro meio, impresso ou digital, em português ou em tradução. 